Article

\title{
Synthesis of a Cyclophosphazene Derivative Containing Multiple Cyano Groups for Electron-Beam Irradiated Flame-Retardant Materials
}

\author{
Bingbing Leng ${ }^{1}$, Jiayu Yang ${ }^{2}$, Chunhui Zhu ${ }^{3}$, Zhipeng Wang ${ }^{1}$, Chengying Shi ${ }^{2}$, Yang Liu ${ }^{4}$, Hongyan Zhang ${ }^{4}$, \\ Wenge $\mathrm{Xu}^{4}$ and Baijun Liu ${ }^{2, *}$
}

1 Changchun Power Supply Company, State Grid (Jilin Province) Electric Power Co., Ltd., 4969 Renmin Street, Changchun 130021, China; lengbingbingmail@sina.com (B.L.); zhipengwang162@163.com (Z.W.)

2 National \& Local Joint Engineering Laboratory for Synthesis Technology of High Performance Polymer, College of Chemistry, Jilin University, 2699 Qianjin Street, Changchun 130012, China; jiayuy20@mails.jlu.edu.cn (J.Y.); sicangying@foxmail.com (C.S.)

3 Economic and Technological Research Institute, State Grid (Jilin Province) Electric Power Co., Ltd., 1427 Pingquan Road, Changchun 130062, China; chunhuizhu163@163.com

4 Changchun Radiation Technology Co., Ltd., China Isotope \& Radiation Corporation (CIRC), 770 Shengye Road, Changchun 130102, China; liuyang@circ.com.cn (Y.L.); zhanghongyan@circ.com.cn (H.Z.); xuwenge@circ.com.cn (W.X.)

* Correspondence: liubj@jlu.edu.cn

check for updates

Citation: Leng, B.; Yang, J.; Zhu, C.; Wang, Z.; Shi, C.; Liu, Y.; Zhang, H.; $\mathrm{Xu}, \mathrm{W}$; Liu, B. Synthesis of a Cyclophosphazene Derivative Containing Multiple Cyano Groups for Electron-Beam Irradiated Flame-Retardant Materials. Polymers 2021, 13, 3460. https://doi.org/ $10.3390 /$ polym 13203460

Academic Editor: Elisabetta Ranucci

Received: 12 September 2021

Accepted: 4 October 2021

Published: 9 October 2021

Publisher's Note: MDPI stays neutral with regard to jurisdictional claims in published maps and institutional affiliations.

Copyright: (c) 2021 by the authors. Licensee MDPI, Basel, Switzerland. This article is an open access article distributed under the terms and conditions of the Creative Commons Attribution (CC BY) license (https:// creativecommons.org/licenses/by/ $4.0 /)$.
Abstract: A cyclophosphazene derivative containing multiple cyano groups, denoted as hexa(4cyanophenoxy)cyclotriphosphazene ( $\mathrm{CN}-\mathrm{CP})$, was synthesized by a one-step nucleophilic substitution reaction for a phosphorus-nitrogen flame retardant. To meet the strict requirement of safe and environment-protective insulation materials, a series of composites based on low-density polyethylenepoly(ethylene-co-vinyl acetate) containing $\mathrm{CN}-\mathrm{CP} / \mathrm{Mg}(\mathrm{OH})_{2} / \mathrm{Al}(\mathrm{OH})_{3}$ organic-inorganic synergistic flame retardants was fabricated. High-energy electron beam irradiation was subsequently applied to obtain a halogen-free flame-retardant crosslinked system. The relationship between crosslinking degree and irradiation dose was studied, and crosslinking degrees ranging within $63-85 \%$ were obtained under 100-190 kGy. Furthermore, the effects of CN-CP filler and irradiation dose on the properties of the composites were carefully investigated. The maximum tensile stress and limiting oxygen index values of most composites irradiated by EB were more than $15 \mathrm{MPa}$ and $28 \%$. Results revealed that the obtained materials had excellent thermal and mechanical, flame-retardant, and insulation properties, thereby suggesting their promising prospects for wire and cable applications.

Keywords: EB-irradiation; cyclophosphazene derivative; crosslinked networks; flame retardancy; wires and cables

\section{Introduction}

Low-density polyethylene (LDPE) is one of the most widely used plastics. It is known for its low cost, easy processability, and excellent mechanical and insulating properties [1]. With the continuous increase in public environmental awareness, nontoxic and halogen-free LDPE is believed to a promising candidate to replace traditional polyvinylchloride as insulation layers in wires and cables [2]. To meet performance requirements, poly(ethylene-co-vinyl acetate) (EVA) elastomer is often introduced into an LDPE matrix to obtain LDPE/EVA blends with improved flexibility, toughness, and resistance to environmental stress cracking of insulations $[3,4]$. Unfortunately, the flammable nature of polyolefins limits their extensive application as wire and cable insulation.

The flame retardancy of polyolefins can be enhanced by the incorporation of organic and inorganic fillers. Owing to the high-efficiency flame-retardant and smoke-suppression effects of some metallic hydroxide fillers (e.g., $\mathrm{Mg}(\mathrm{OH})_{2}$ and $\mathrm{Al}(\mathrm{OH})_{3}$ nanoparticles), 
they are widely applied in halogen-free flame-retardant materials [5,6]. However, several unfavorable phenomena are often observed when these inorganic fillers are introduced into the polymer matrix. To provide adequate flame-retardancy effects, an extremely high loading amount of metallic hydroxides (e.g., $\geq 65 \%$ ) must be present in the composites [7]. The high content of inorganic particles in the polymer matrix always leads to a significant deterioration of flexibility and other properties. To improve the compatibility between the organic matrix and inorganic fillers, the fillers (e.g., $\mathrm{Mg}(\mathrm{OH})_{2}$ and $\left.\mathrm{Al}(\mathrm{OH})_{3}\right)$ have to be ground into nanoparticles and then treated by surfactants [8-10]. Therefore, the development of novel compound flame retardants is important to replace or partially replace currently used inorganic flame retardants.

Crosslinking is a critical approach to improving the thermomechanical properties and chemical resistance of LDPE-based materials. Compared with chemical crosslinking, electron-beam (EB) crosslinking has many advantages [11-13], including the following: (1) crosslinking occurs in the absence of any catalyst, which avoids the residue of small molecules in the products; (2) crosslinking is fast and clean, which is suitable for industrial production; (3) crosslinking degree is precisely controllable by the irradiation dosage; and (4) crosslinking reaction can be conducted at room temperature. Several investigations have indicated that the blends of LDPE and EVA are susceptible to the formation of integrated crosslinked networks under EB-irradiation [14,15]. Cyclophosphazene derivatives (CPs) are believed to be a family of highly efficient flame retardants because of their unique nitrogen/phosphorus-rich heterocyclic structure, which may exert synergistic effects on the improvement of flame-retardant performance [16]. For instance, an allyl-functionalized $\mathrm{CP}$ has been incorporated into poly(ethylene terephthalate) to form a flame-resistant blend with a limiting oxygen index (LOI) value of $33.5 \%$, which was much higher than that (26.5\%) of pure PET [17]. However, few CPs have been investigated for EB-irradiated flame retardant PE/EVA blends.

In the current study, a CP containing multiple cyano groups was synthesized through a fast and simple nucleophilic substitution reaction. The $\mathrm{CP}$ can serve as a complexed halogen-free flame retardant together with $\mathrm{Mg}(\mathrm{OH})_{2}$ and $\mathrm{Al}(\mathrm{OH})_{3}$ particles and an irradiation sensitizer in a PE/EVA blend. Its high phosphorus and nitrogen contents and large number of polar cyano groups were expected to improve flame retardancy and enhance interactions among various components in the PE/EVA system. The properties of the composites after EB-irradiation at different doses were thoroughly investigated. The crosslinked PE/EVA-based composites containing organic-inorganic complex flame retardants after EB-irradiation were confirmed to have many attractive properties for wire and cable applications.

\section{Materials and Methods}

\subsection{Materials}

LDPE was purchased from LG Chem, Ltd. (Yeoui-daero Yeongdeungpo-gu Seoul, Seoul, Korea), and its number-average molecular weight of LDPE was about 150,000-250,000. Poly(ethylene-co-vinyl acetate) (VA content: 15\%) was obtained from Shanghai PUEN Chemical Co., Ltd. (Shanghai, China). $\mathrm{Mg}(\mathrm{OH})_{2}$ and $\mathrm{Al}(\mathrm{OH})_{3}$ particles (industrial grade) were purchased from Zibo Chenyu Fine Powder Co., Ltd., (Shandong, China). Hexachlorocyclotriphosphazene (99\%) was obtained from Wuhan Hezhong Bio-chemical Manufacture Co., Ltd., (Wuhan, China). 4-Cyanophenol (98\%) was supplied by Shanghai Aladdin Biochemical Technology Co., Ltd., China. Potassium carbonate $\left(\mathrm{K}_{2} \mathrm{CO}_{3}, 99 \%\right)$ was obtained from Sinopharm Chemical Reagent Co., Ltd., (Shanghai, China). All other chemicals and reagents were from commercial resources and used without purification.

\subsection{Instruments and Measurements}

Fourier transform infrared spectroscopy (FTIR) was carried out on a Nicolet Impact 410 spectrometer at $4000-400 \mathrm{~cm}^{-1}$. Proton nuclear magnetic resonance $\left({ }^{1} \mathrm{H} \mathrm{NMR}\right) \mathrm{spec}-$ troscopy was run on a Bruker 510 spectrometer $(500 \mathrm{MHz})$, and $\mathrm{CDCl}_{3}$ was selected as 
a solvent. The microstructure of the membranes was observed on a Nova NanoSEM 450 scanning electron microscopy (FEI Company, Hillsboro, OR, USA). Thermogravimetric analysis (TGA) was conducted on a Perkin Elmer Pyris-1 instrument under $\mathrm{N}_{2}$ at a heating rate of $10^{\circ} \mathrm{C} \cdot \mathrm{min}^{-1}$.

A SHIMADZU AG-I 1KN instrument was used to test the mechanical properties of the membranes $(15 \mathrm{~mm} \times 5 \mathrm{~mm})$ at a strain rate of $2 \mathrm{~mm} \cdot \mathrm{min}^{-1}$.

Sheets were irradiated using an electron accelerator (Rhodotron TT200, Louvain-laNeuve, Belgium) with $3 \mathrm{MeV}$ energy under various irradiation doses (100-190 kGy).

The gel content of the crosslinked samples was tested using an extraction method, and xylene was used as solvent.

LOI measurements were carried out on an M606B oxygen-index apparatus (China). The specimen dimensions were $4 \mathrm{~mm} \times 10 \mathrm{~mm} \times 100 \mathrm{~mm}$.

The UL-94 vertical burning level was tested on an FTT0082 instrument (Fire Testing Technology, East Grinstead, UK) according to ASTM 3801. The sample dimensions were $125 \mathrm{~mm} \times 12.7 \mathrm{~mm} \times 3.2 \mathrm{~mm}$.

Surface and volume resistance were measured at room temperature by using a ZC-90F teraohmmeter (Shanghai Hanyi Electrical Technology Co., Ltd., Shanghai, China).

A dielectric-loss measurement system (model Automatic LCR Meter 4225; Tianji Anfutai Electrical Technology Co., Ltd., Tianjin, China) was used to determine the dielectric constant and the dielectric-loss tangent of the samples.

\subsection{Synthesis of a Cyano-Functionalized $C P$}

We added $17.2 \mathrm{~g}(0.144 \mathrm{~mol})$ of 4-hydroxybenzonitrile, $21.9 \mathrm{~g}(0.16 \mathrm{~mol})$ of $\mathrm{K}_{2} \mathrm{CO}_{3}$, and $200 \mathrm{~mL}$ of acetone into a $500 \mathrm{~mL}$ three-necked flask equipped with a condenser and a mechanical stirrer. After stirring at reflux temperature under $\mathrm{N}_{2}$ for $4 \mathrm{~h}$, a solution of $6.953 \mathrm{~g}$ $(0.02 \mathrm{~mol})$ of hexachlorocyclotriphosphazene in $20 \mathrm{~mL}$ of acetone was added dropwise into the reaction mixture. The reaction was continued at $56^{\circ} \mathrm{C}$ for another $6 \mathrm{~h}$, and the solution was poured into deionized water. The precipitate was washed with deionized water and acetone three times, and a white powder was obtained. After drying in a vacuum oven at $80{ }^{\circ} \mathrm{C}$ for $12 \mathrm{~h}$, hexa(4-cyanophenoxy)cyclotriphosphazene $(\mathrm{CN}-\mathrm{CP})$ was obtained (Scheme 1). The yield was about $83 \%$.
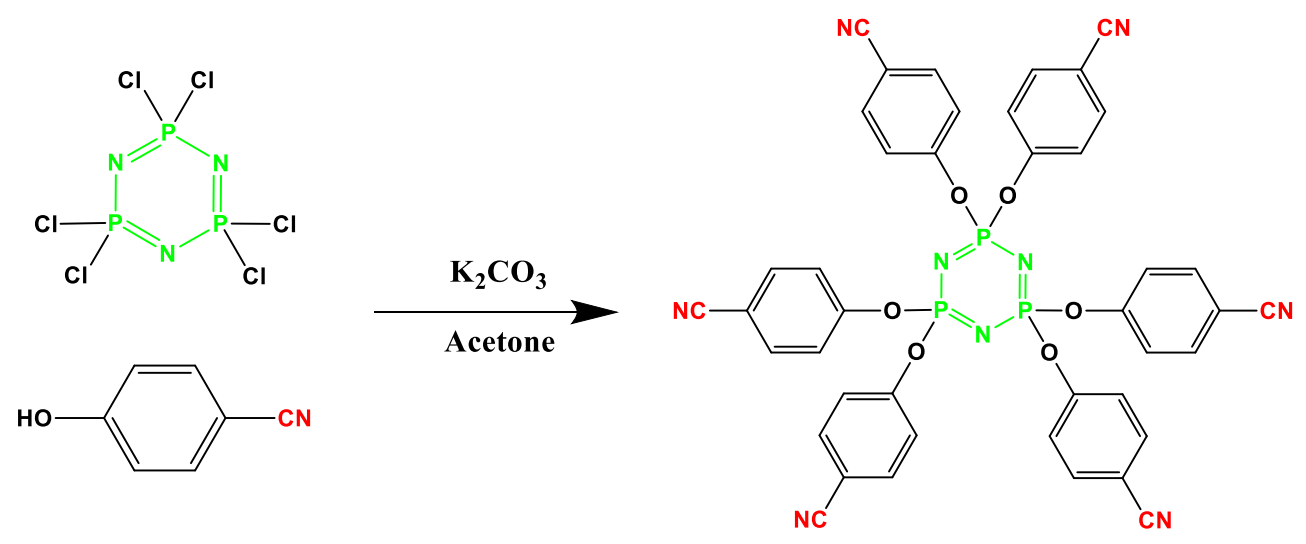

Scheme 1. Synthesis route of CN-CP.

\subsection{Preparation of Insulation-Composite Materials Containing Inorganic-Organic Flame Retardants}

Halogen-free flame-retardant insulation-composite materials containing LDPE, EVA, $\mathrm{Mg}(\mathrm{OH})_{2}, \mathrm{Al}(\mathrm{OH})_{3}$, and $\mathrm{CN}-\mathrm{CP}$ were prepared using a melt-blending method at $125^{\circ} \mathrm{C}$ with an open mill followed by a hot-pressing mold at $125^{\circ} \mathrm{C}$ under $3.0 \mathrm{MPa}$ with a plate vulcanizing machine. According to the formulation illustrated in Table 1, the samples were denoted as PE-CN-X $(X=0,1,2,3,4$, and 5). 
Table 1. Formulation of insulation materials.

\begin{tabular}{cccccc}
\hline Sample & $\begin{array}{c}\text { PE } \\
\text { (phr) }\end{array}$ & $\begin{array}{c}\text { EVA } \\
\text { (phr) }\end{array}$ & $\begin{array}{c}\mathbf{M g}(\mathbf{O H})_{2} \\
(\mathbf{p h r})\end{array}$ & $\begin{array}{c}\text { Al(OH) } \\
\text { (phr) }\end{array}$ & $\begin{array}{c}\text { HPCTP-CN } \\
\text { (phr) }\end{array}$ \\
\hline PE-CN-0 & 100 & 40 & 100 & 100 & 0 \\
PE-CN-1 & 100 & 40 & 100 & 100 & 2 \\
PE-CN-2 & 100 & 40 & 100 & 100 & 5 \\
PE-CN-3 & 100 & 40 & 100 & 100 & 8 \\
PE-CN-4 & 100 & 40 & 100 & 100 & 10 \\
PE-CN-5 & 100 & 40 & 100 & 100 & 15 \\
\hline
\end{tabular}

\subsection{Preparation of EB-Irradiated Insulation Materials}

The obtained sheets were irradiated with a high-energy $(3.0 \mathrm{MeV})$ electron accelerator under various irradiation doses (100-190 kGy). Finally, crosslinked composites with different crosslinking degrees were obtained for further performance investigation.

\section{Results and Discussion}

\subsection{Synthesis of Multiple Cyano-Containing CP as Organic Flame Retardant}

The development of novel organic flame retardants for use in insulation materials is continuously required [18-20]. CPs usually have high contents of phosphorus and nitrogen elements, which may play important roles in flame retardancy [21,22]. In the current study, multiple cyano groups $(-\mathrm{CN})$ were readily attached onto a cyclotriphosphazene unit under mild conditions via nucleophilic substitution (Scheme 1). The product was named $\mathrm{CN}-\mathrm{CP}$, and it possessed a unique six-arm chemical structure bearing polar $-\mathrm{C} \equiv \mathrm{N}$ groups.

FTIR, ${ }^{1} \mathrm{H}$ NMR, and elemental analyses were used to identify the chemical structure of CN-CP. In its FTIR spectrum (Figure 1a), $1205 \mathrm{~cm}^{-1}$ belonged to the characteristic absorption peak of $\mathrm{P}=\mathrm{N}$, and 939 and $1105 \mathrm{~cm}^{-1}$ were the characteristic absorption peaks of $\mathrm{P}-\mathrm{O}-\mathrm{C}$. A strong absorption at $2227 \mathrm{~cm}^{-1}$ caused by $-\mathrm{CN}$ groups was clearly observed. In its ${ }^{1} \mathrm{H}$ NMR spectrum (Figure $1 \mathrm{~b}$ ), doublets appeared at 7.61 and $7.12 \mathrm{ppm}$ from H2 and $\mathrm{H} 1$ on the benzene ring of $\mathrm{CN}-\mathrm{CP}$, separate from the characteristic absorption of deuterated chloroform at $7.26 \mathrm{ppm}$. Results of elemental analysis $(\mathrm{C}=76.674 \%, \mathrm{H}=3.956 \%$, $\mathrm{N}=19.370 \%)$ for $\mathrm{CN}-\mathrm{CP}$ were relatively close to its theoretical values $\left(\mathrm{C}_{42} \mathrm{H}_{8} \mathrm{O}_{6} \mathrm{~N}_{9} \mathrm{P}_{3}\right.$ : $\mathrm{C}=77.051 \%, \mathrm{H}=3.695 \%, \mathrm{~N}=19.255 \%$ )
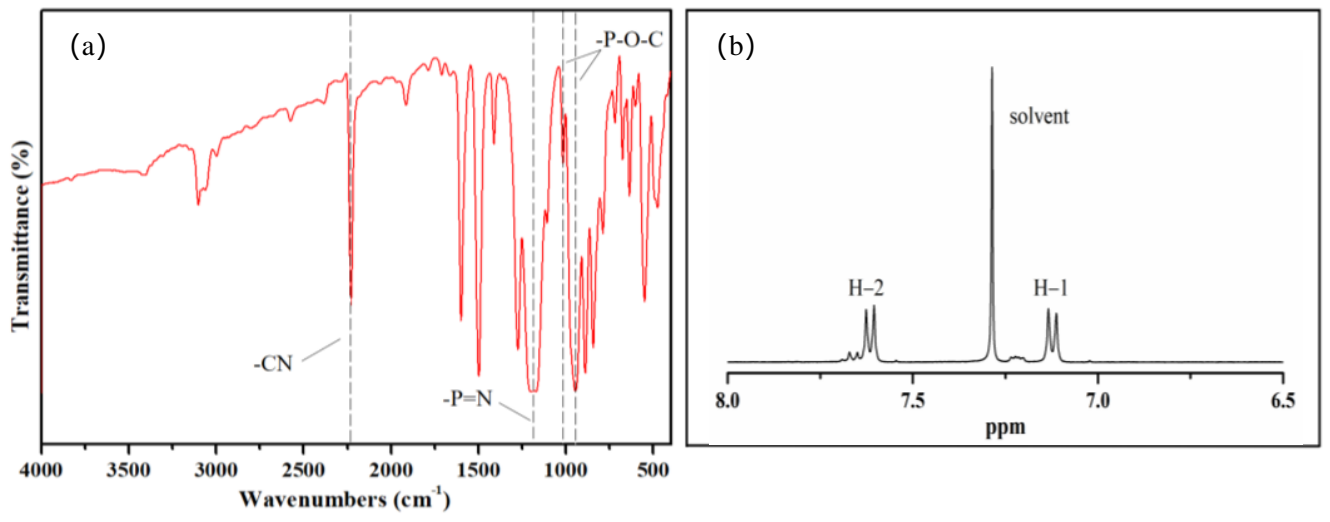

Figure 1. FTIR (a) and ${ }^{1} \mathrm{H}$ NMR (b) spectra of $\mathrm{CN}-\mathrm{CP}$.

\subsection{Preparation of EB-Irradiated LDPE/EVA Composites Containing CN-CP}

As is illustrated by the formulation in Table 1, halogen-free flame-retardant composites were prepared using a melting-blending process. To evaluate the effect of $\mathrm{CN}-\mathrm{CP}$ on processability, the melt index of the composites with different $\mathrm{CN}-\mathrm{CP}$ contents was determined. As is shown in Figure 2a, the incorporation of $\mathrm{CN}-\mathrm{CP}$ slightly improved the melt index, and PE-CN-1 containing $2 \mathrm{~g} \mathrm{CN}-\mathrm{CP}$ showed the highest value of $2.6 \mathrm{~g} / 10 \mathrm{~min}$. 

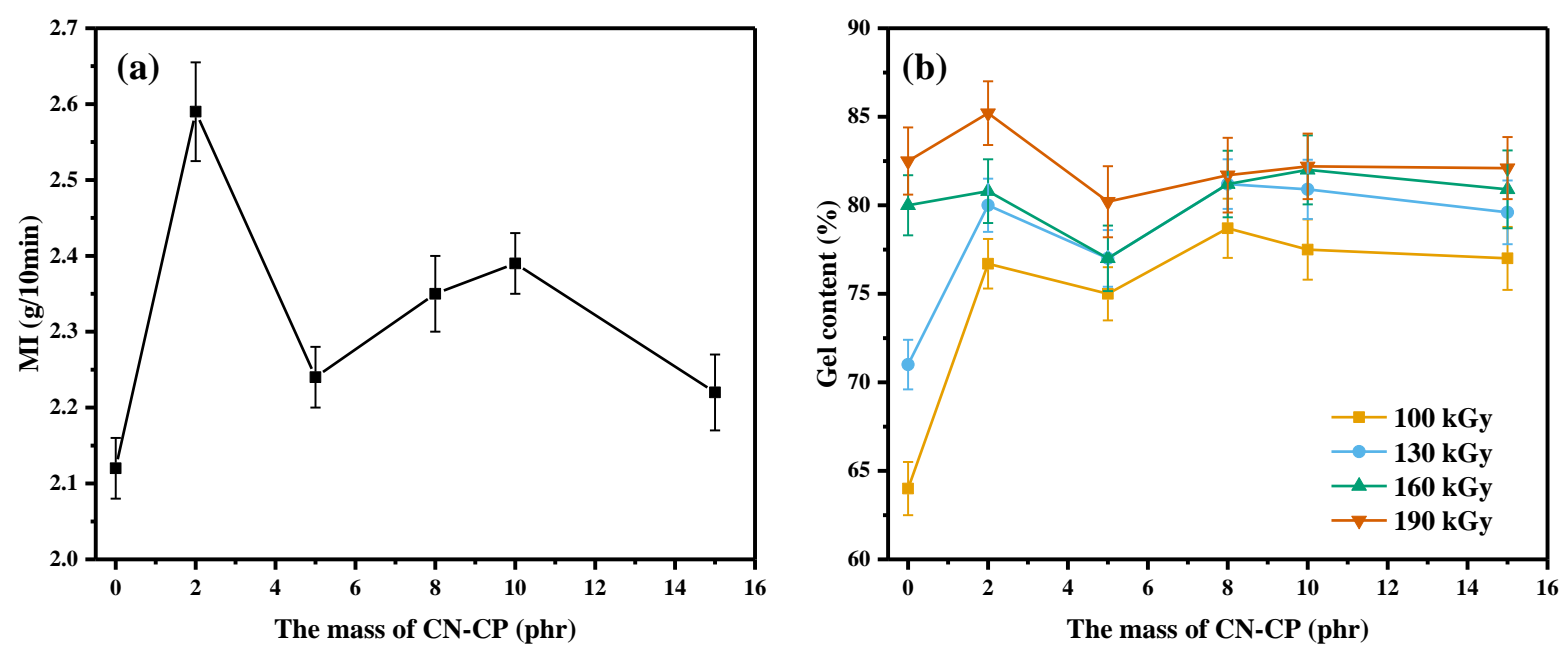

Figure 2. Melt index (a) and relationship between radiation dose and gel content (b) of the composites.

EB-irradiation was applied to yield stable, crosslinked PE/EVA networks as an efficient method of enhancing mechanical strength and heat resistance. In many cases, a high crosslinking degree above $70 \%$ is needed for PE-based materials to be used in the field of cables and tubes. In the present study, the crosslinking degree of composites was evaluated by measuring gel content after irradiation at doses of 100, 130, 160, and $190 \mathrm{kGy}$. Figure 2b shows that for each sample, a higher irradiation dose always led to a higher crosslinking degree. Under the highest irradiation dose of $190 \mathrm{kGy}$, the crosslinking degrees of all test samples exceeded $80 \%$. Notably, the $\mathrm{CN}-\mathrm{CP}$ filled composites always exhibited higher crosslinking degrees than those without $\mathrm{CN}-\mathrm{CP}(\mathrm{PE}-\mathrm{CN}-0)$. We deduced that $\mathrm{CN}-\mathrm{CP}$ with unsaturated $\mathrm{C} \equiv \mathrm{N}$ and $\mathrm{P}=\mathrm{N}$ groups may serve as an irradiation-crosslinking sensitizer and play a role in promoting the irradiation crosslinking of the composites.

Diagrams of composite preparation and EB-irradiation processes are presented in Figure 3. The above analyses confirmed that upon EB-irradiation, highly crosslinked $\mathrm{PE} /$ EVA networks, in which organic $\mathrm{CN}-\mathrm{CP}$ and inorganic $\mathrm{Mg}(\mathrm{OH})_{2} / \mathrm{Al}(\mathrm{OH})_{3}$ particles were distributed, were fabricated. This composition can be expected to have the desired combination of high strength, good heat resistance, sufficient flexibility, and excellent flame retardancy.

\section{a. Before EB-irradiation}

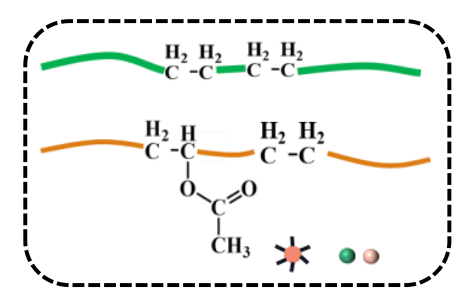

b. EB-irradiation

$\mathrm{f}_{\mathrm{C}}^{\mathrm{H}_{2}}-\mathrm{C}_{\mathrm{C}}^{\mathrm{H}_{2}}+\longrightarrow \mathrm{f}_{\mathrm{C}}^{\mathrm{C}_{2}}$

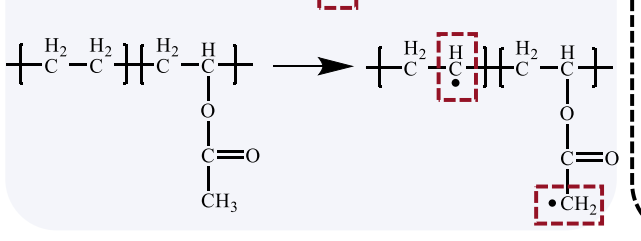

\section{c. After EB-irradiation}
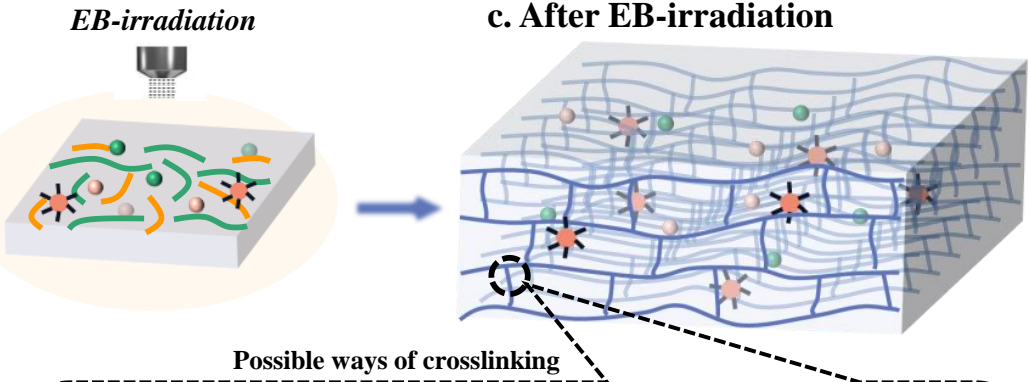

Possible ways of crosslinking

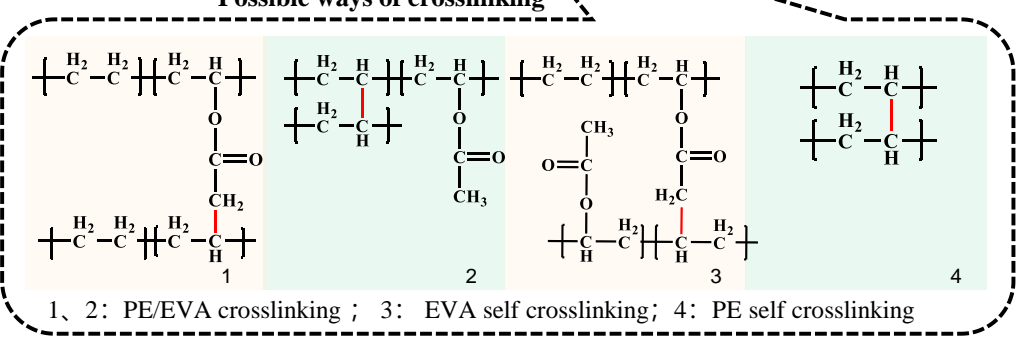

Figure 3. Illustration of crosslinked PE/EVA networks containing organic-inorganic flame retardants. 


\subsection{Morphology of Composites}

The morphology of $\mathrm{CN}-\mathrm{CP}$ powder and its composites was investigated by SEM; the results are shown in Figure 4. The size of $\mathrm{CN}-\mathrm{CP}$ powder before blending was around 20-40 $\mu \mathrm{m}$ (Figure 4a). For all composite samples, fillers including $\mathrm{CN}-\mathrm{CP}$ and inorganic $\mathrm{Mg}(\mathrm{OH})_{2} / \mathrm{Al}(\mathrm{OH})_{3}$ powder were evenly dispersed in the LDPE/EVA matrix (Figure 4b-f). Even at a higher load of $\mathrm{CN}-\mathrm{CP}$, no obvious aggregation of fillers was observed. This finding was due to $\mathrm{CN}-\mathrm{CP}$ being an organic substance, i.e., it had good affinity for the PE/EVA matrix.
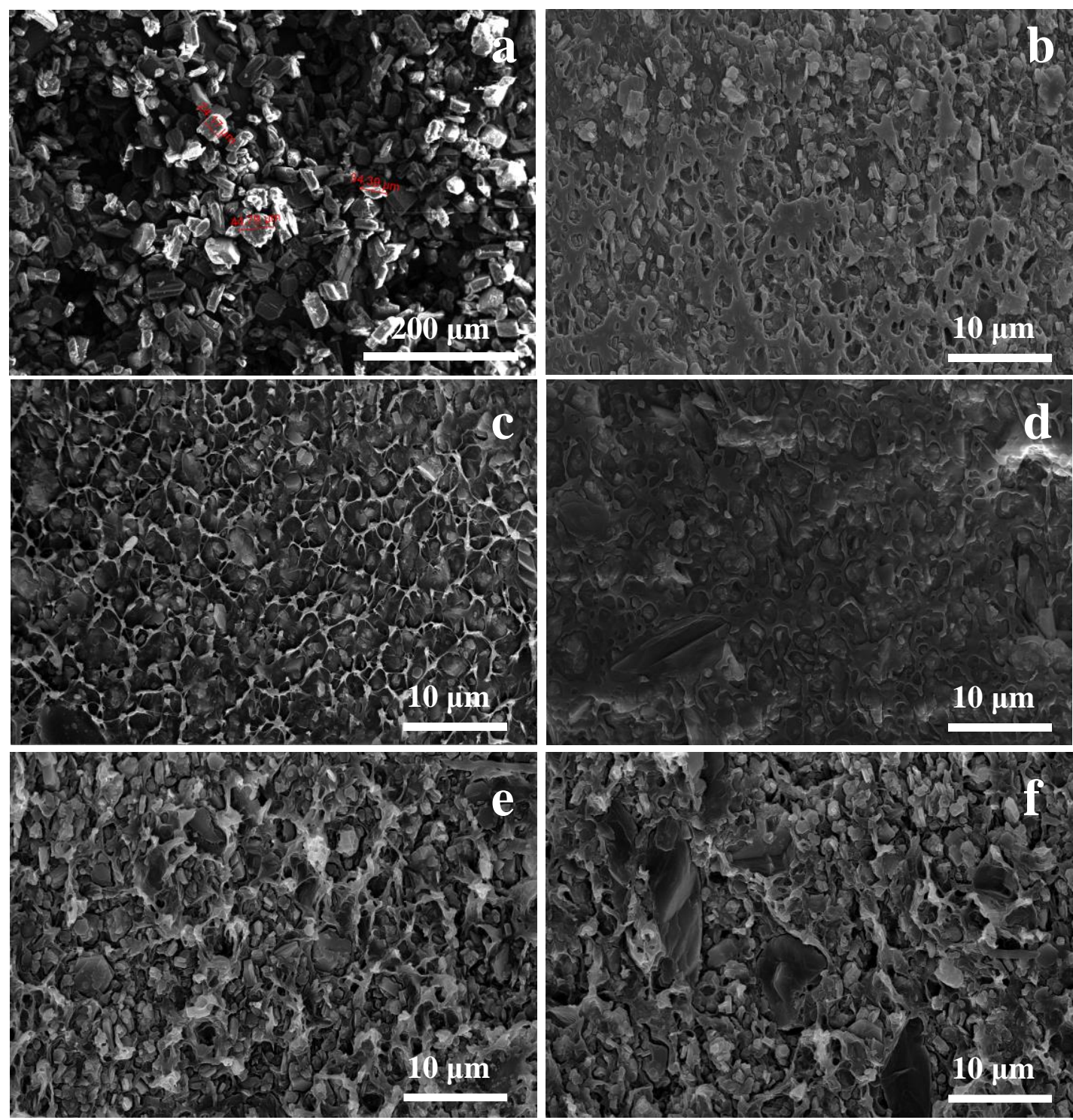

Figure 4. SEM images of CN-CP powder and its composites (a) CN-CP powder; (b) PE-CN-1; (c) PE-CN-2; (d) PE-CN-3; (e) PE-CN-4; (f) PE-CN-5.

The EDX mapping images of N, P, Al, and Mg elements for the PE-CN-5 sample with a high $\mathrm{CN}-\mathrm{CP}$ content are shown in Figure 5. We observed that N/P elements from organic fillers and $\mathrm{Al} / \mathrm{Mg}$ elements from inorganic fillers were uniformly dispersed throughout the composites. Additionally, no Cl element was observed in the EDS spectrum, suggesting a complete substitution reaction during the preparation process of the $\mathrm{CN}-\mathrm{CP}$ flame retardant. 


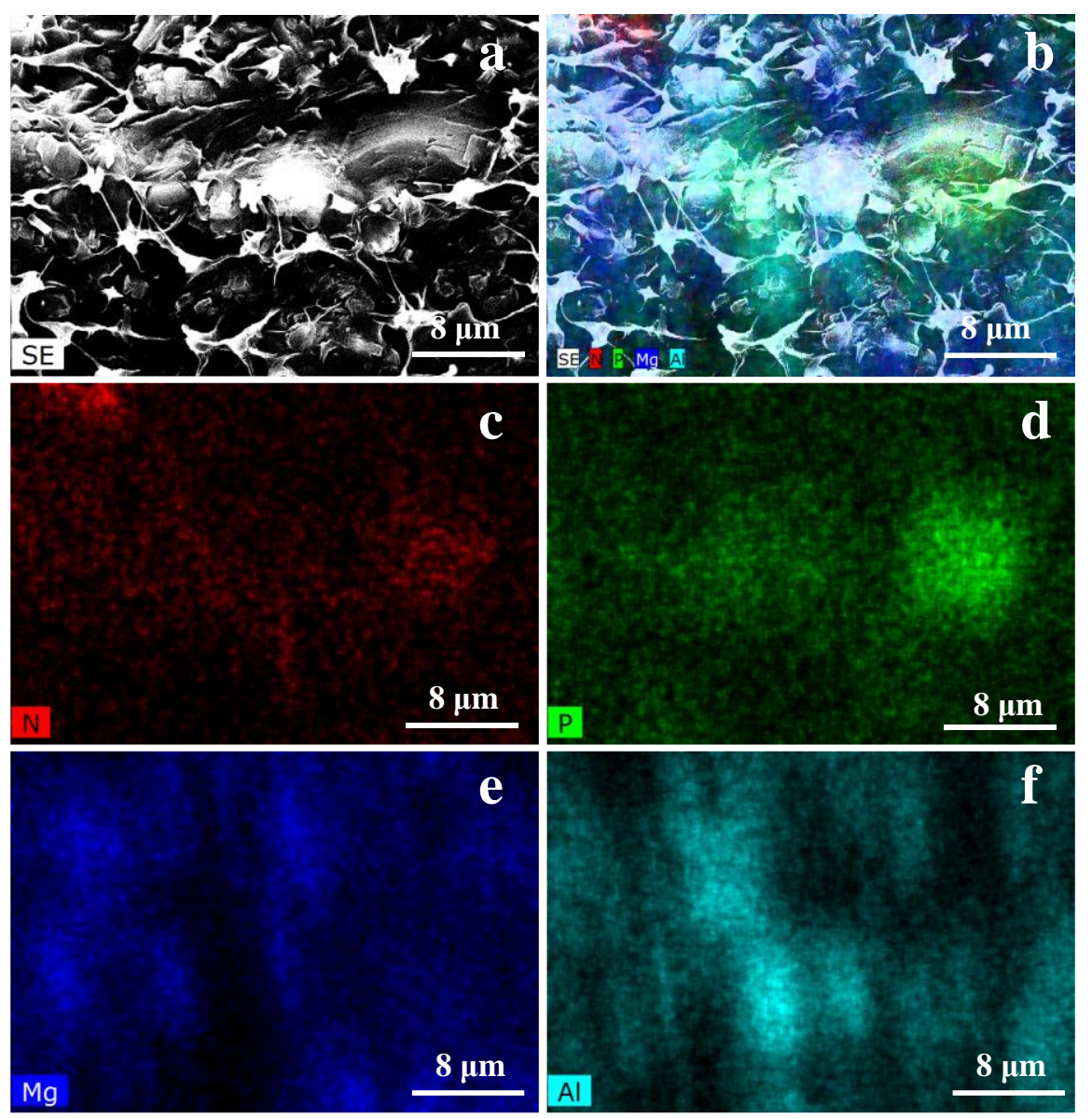

Figure 5. SEM (a) and EDS images (b-f) of PE-CN-5.

\subsection{Thermal and Mechanical Properties}

The thermal stability of the composites was evaluated by TGA in air. We found that no thermal weight loss occurred below $200^{\circ} \mathrm{C}$, and the composites began to lose weight beyond $250{ }^{\circ} \mathrm{C}$ owing to the degradation of LDPE and EVA. CN-CP introduction and EB-irradiation treatment had no serious influence on the thermal stability of the composites. The residues at $700{ }^{\circ} \mathrm{C}$ of the crosslinked samples ranged within $20-30 \%$, and they were believed to be caused by the $\mathrm{Mg}(\mathrm{OH})_{2} / \mathrm{Al}(\mathrm{OH})_{3}$ fillers.

We subsequently conducted the tensile test of the composites before and after irradiation was conducted, as summarized in Figure 6. Results showed that the maximum tensile strength of the composites increased with increased irradiation dose, indicating that EB-irradiation helped improve the tensile strength of the composites. Furthermore, higher irradiation doses ( $>130 \mathrm{kGy}$ ) caused the simultaneous occurrence of crosslinking and degradation of the LDPE and EVA molecular chains, leading to a more complicated effect on tensile properties. This contradiction brought a fluctuation to the increasing trend of the strengths (Figure 6a). In some cases, the incorporation of $\mathrm{CN}-\mathrm{CP}$ components even led to improved tensile properties. For example, at $100 \mathrm{kGy}$, the tensile strengths of PE$\mathrm{CN}-1$ and PE-CN-3 reached 16.61 and $16.54 \mathrm{MPa}$, which were higher than that (16.27 MPa) of PE-CN-0. PE-CN-1 and PE-CN-4 also had enhanced elongations at break compared with $\mathrm{PE}-\mathrm{CN}-0$ without $\mathrm{CN}-\mathrm{CP}$ filler. Overall, the maximum tensile strength and elongation at break of most composites irradiated by high-energy EB were more than $15 \mathrm{MPa}$ and $100 \%$, respectively. These desired mechanical properties provided sufficient strength and flexibility for the composites to be used in wires and cables. 

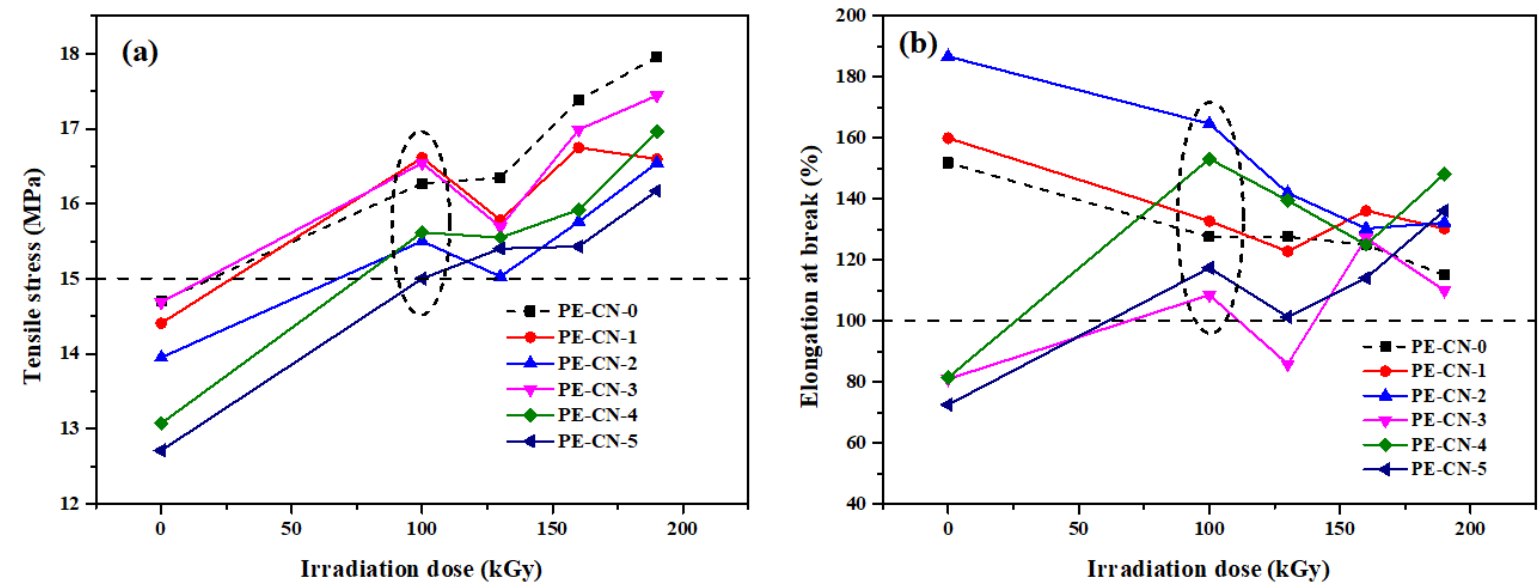

Figure 6. Tensile stress (a) and elongation at break (b) of the composites under different irradiation doses.

\subsection{Flame-Retardancy and Electrical-Insulation Properties}

The LOI of the composites under different irradiation doses was tested to evaluate their flame retardancy (Figure 7). Flame-retardant contents and irradiation doses clearly affected flame retardancy. First, current organic-inorganic synergistic flame retardants $\left(\mathrm{CN}-\mathrm{CP} / \mathrm{Mg}(\mathrm{OH})_{2} / \mathrm{Al}(\mathrm{OH})_{3}\right)$ exhibited excellent flame-retardant performance. The LOI values of PE-CN-1, 2, 3, 4, and 5 ranged within 26-33\%, which was much higher than that $(17.6 \%)$ of the pristine LDPE/EVA sample. Second, high-energy EB-irradiation played a significant role in increasing LOI values, and samples treated at a higher dose generally had a higher LOI value. For instance, at 190 kGy, the LOI value of PE-CN-4 was 33\%, which was $26.9 \%$ higher than that of the sample without irradiation. The vertical burning levels of PE-CN-1, 2, 3, 4, and 5 containing organic-inorganic flame retardants reached V-1 and $\mathrm{V}-0$, and it was confirmed that the $\mathrm{CN}-\mathrm{CP}$ organic filler helped enhance the burning level (Table 2).

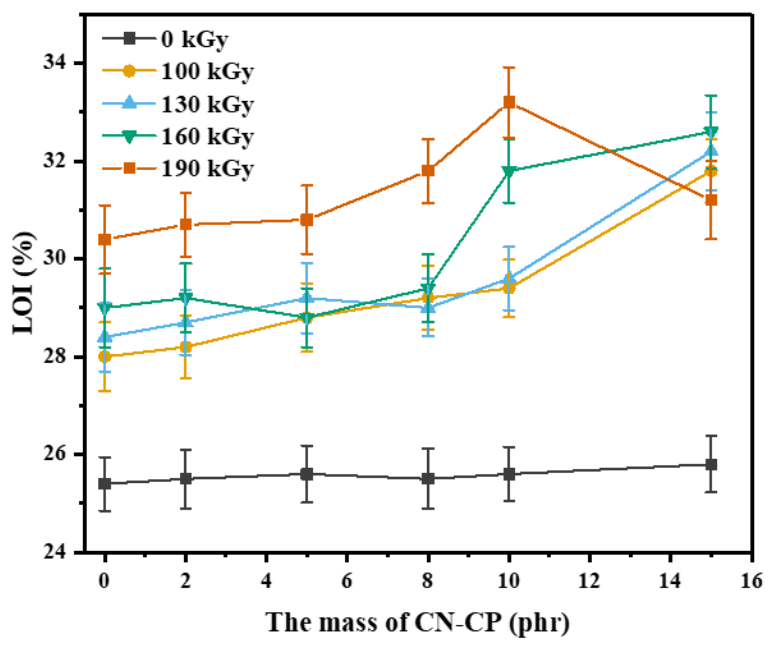

Figure 7. Limiting oxygen index (LOI) of the composites under different irradiation doses.

Resistance, volume resistivity, relative permittivity, and capacitance were measured to characterize the insulation performance of the halogen-free flame retardant composites. As is shown in Table 2, the introduction of $\mathrm{CN}-\mathrm{CP}$ filler had no obvious effect on the insulation properties of the composites. Resistance and volume resistivity were above $1.9 \times 10^{12} \Omega$ and $4.0 \times 10^{14} \Omega \cdot \mathrm{cm}$, respectively. Relative permittivity and capacitance were above 2.6 and $50 \mathrm{pF}$, respectively. Clearly, these properties met the requirements of wire and cable insulation materials. 
Table 2. UL-94 vertical burning level and insulation properties of PE-CN composites.

\begin{tabular}{cccccc}
\hline Sample & UL-94 & Resistance $(\Omega)$ & $\begin{array}{c}\text { Volume } \\
\text { Resistivity }(\boldsymbol{\Omega} \cdot \mathbf{c m})\end{array}$ & Capacitance(pF) & Permittivity \\
\hline PE-CN-0 & NR & $2.75 \times 10^{12}$ & $5.68 \times 10^{14}$ & 55 & 2.8 \\
PE-CN-1 & V-1 & $1.90 \times 10^{12}$ & $4.23 \times 10^{14}$ & 56 & 2.6 \\
PE-CN-2 & V-0 & $2.70 \times 10^{12}$ & $5.41 \times 10^{14}$ & 54 & 2.8 \\
PE-CN-3 & V-0 & $2.81 \times 10^{12}$ & $5.52 \times 10^{14}$ & 53 & 2.8 \\
PE-CN-4 & V-0 & $3.22 \times 10^{12}$ & $6.02 \times 10^{14}$ & 50 & 2.8 \\
PE-CN-5 & V-0 & $2.00 \times 10^{12}$ & $4.05 \times 10^{14}$ & 55 & 2.8 \\
\hline
\end{tabular}

\section{Conclusions}

Based on the successful synthesis of a cyano-functionalized $\mathrm{CN}$, a new family of halogen-free flame-retardant insulating materials comprised of an LDPE/EVA matrix and organic-inorganic synergistic flame retardants were fabricated for wire and cable applications. High-energy EB-irradiation was used to prepare crosslinked networks and enhance the performance of the composites. The relationships among properties, composition, and irradiation dose were carefully investigated. EB-irradiated composites were found to exhibit many attractive properties, including high mechanical strength (tensile stress: $\geq 15 \mathrm{MPa}$ ), excellent flame retardancy (LOI: 25.2-33.0\%), and good electrical-insulating properties (resistance: $\geq 1.9 \times 10^{12} \Omega$; volume resistivity: $\left.\geq 4.0 \times 10^{14} \Omega \cdot \mathrm{cm}\right)$. These combined findings suggest promising application prospects for these PE/EVA-based insulating materials.

Author Contributions: Conceptualization, B.L. (Bingbing Leng) and J.Y.; methodology, C.S.; software, J.Y.; validation, Z.W., C.Z. and Y.L.; formal analysis, J.Y.; investigation, C.S.; resources, W.X.; data curation, B.L. (Baijun Liu); writing — original draft preparation, B.L. (Bingbing Leng) and J.Y.; writingreview and editing, B.L. (Baijun Liu); visualization, Z.W.; supervision, B.L. (Baijun Liu); project administration, W.X.; funding acquisition, H.Z. All authors have read and agreed to the published version of the manuscript.

Funding: This research was funded by the Science and Technology Project of State Grid Jilin Electric Power Co., Ltd., China (No. SGJLCC00KJJS2101813).

Institutional Review Board Statement: Not applicable.

Informed Consent Statement: Not applicable.

Data Availability Statement: Not applicable.

Conflicts of Interest: The authors declare no conflict of interest.

\section{References}

1. Spalding, M.A.; Chatterjee, A.M. Handbook of Industrial Polyethylene and Technology: Definitive Guide to Manufacturing, Properties, Processing, Applications and Markets (Part Two); John Wiley \& Sons: Hoboken, NJ, USA, 2018; pp. 105-138.

2. Dadbin, S.; Frounchi, M.; Haji, S.M.; Gangi, F. Molecular structure and physical properties of electron beam-crosslinked lowdensity polyethylene for wire and cable insulation applications. J. Appl. Polym. Sci. 2002, 86, 1959-1969. [CrossRef]

3. Haurie, L.; Fernández, A.L.; Velasco, J.C.; Chimenos, J.M.; Lopez-Cuesta, J.M.; Espiell, F. Thermal stability and flame retardancy of LDPE/EVA blends filled with synthetic hydromagnesite/aluminium hydroxide/montmorillonite and magnesium hydroxide/aluminium hydroxide/montmorillonite mixtures. Polym. Degrad. Stabil. 2007, 92, 1082-1087. [CrossRef]

4. Sabet, M.; Hassan, A.; Ratnam, C.T. Electron beam irradiation of low density polyethylene/ethylene vinyl acetate filled with metal hydroxides for wire and cable applications. Polym. Degrad. Stabil. 2012, 97, 1432-1467. [CrossRef]

5. Laoutid, F.; Gaudon, P.; Taulemesse, J.M.; Lopez-Cuesta, J.M.; Velasco, J.I.; Piechaczyk, A. Study of hydromagnesite and magnesium hydroxide based fire retardant systems for ethylene vinyl acetate containing organo-modified montmorillonite. Polym. Degrad. Stabil. 2006, 91, 3074-3082. [CrossRef]

6. Jiao, C.M.; Wang, Z.Z.; Ye, Z.; Hu, Y.; Fan, W.C. Flame Retardation of Ethylene-Vinyl Acetate Copolymer Using Nano Magnesium Hydroxide and Nano Hydrotalcite. J. Fire Sci. 2006, 24, 47-64. [CrossRef]

7. Bahattab, M.A.; Mosnacek, J.; Basfar, A. Gross-linked poly(ethylene vinyl acetate) (EVA)/low density polyethylene (LDPE)/metal hydroxides composites for wire and cable applications. Polym. Bull. 2010, 64, 569-580. [CrossRef] 
8. Liu, H.; Alkadasi, N.A.; Zhu, Y.; Tong, L.F.; Fang, Z.P.; Wang, Y.C. Electron beam irradiated HDPE/EVA/Mg(OH) 2 composites for flame-retardant electric cables. Front. Mater. Sci. China 2008, 2, 426-429. [CrossRef]

9. Sener, A.A.; Demirhan, E. The investigation of using magnesium hydroxide as a flame retardant in the cable insulation material by cross-linked polyethylene. Mater. Design. 2008, 29, 1376-1379. [CrossRef]

10. Vahabi, H.; Laoutid, F.; Mehrpouya, M.; RezaSaeb, M.; Dubois, P. Flame retardant polymer materials: An update and the future for 3D printing developments. Mater. Sci. Eng. R. 2021, 144, 100604. [CrossRef]

11. Dadbin, S.; Frounchi, M.; Sabet, M. Studies on the properties and structure of electron-beam crosslinked low-density polyethylene/poly[ethylene-co-(vinyl acetate)] blends. Polym. Int. 2005, 54, 686-691. [CrossRef]

12. Shi, C.Y.; Yang, J.Y.; Liu, Y.; Wang, Y.M.; Xu, W.G.; Xu, Y.Q.; Hu, W.; Liu, B.J. Thermally Conductive Study of Polyethylene/ $\mathrm{Al}_{2} \mathrm{O}_{3}$ Composite Networks Cross-linked by Electron Beam Irradiation. Chem. Res. Chin. Univ. 2020, 36, 940-945. [CrossRef]

13. Salehi SM, A.; Mirjalili, G.; Amrollahi, J. Effects of high-energy electron beam on low-density polyethylene materials containing EVA. J. Appl. Polym. Sci. 2004, 92, 1049-1052. [CrossRef]

14. Sharif, J.; Aziz, S.H.S.A.; Hashim, K. Radiation effects on LDPE/EVA blends. Rad. Phys. Chem. 2000, 58, 191-195. [CrossRef]

15. Zhou, S.; Ning, M.; Wang, X.; Yan, Z.; Guo, D.; He, Q.; Zhang, Y.; She, S.; Hu, Y. The influence of $\gamma$-irradiation on the mechanical, thermal degradation, and flame retardant properties of EVA/LDPE/ATH blends. J. Therm. Anal. Calorim. 2015, 119, 167-173. [CrossRef]

16. Ning, K.; Zhou, L.L.; Zhao, B. A novel aminothiazole-based cyclotriphosphazene derivate towards epoxy resins for high flame retardancy and smoke suppression. Polym. Degrad. Stabil. 2021, 190, 109651. [CrossRef]

17. Kuan, J.F.; Lin, K.F. Synthesis of hexa-allylamino-cyclotriphosphazene as a reactive fire retardant for unsaturated polyesters. J. Appl. Polym. Sci. 2004, 91, 697-702. [CrossRef]

18. Mathew, D.; Reghunadhan Nair, C.P.; Ninan, K.N. Phosphazene-triazine cyclomatrix network polymers: Some aspects of synthesis, thermal- and flame-retardant characteristics. Polym. Int. 2000, 49, 48-56. [CrossRef]

19. Lu, S.Y.; Hamerton, I. Recent developments in the chemistry of halogen-free flame retardant polymers. Prog. Polym. Sci. 2002, 27, 1661-1712. [CrossRef]

20. Qiu, S.L.; Wang, X.; Yu, B.; Feng, X.M.; Mu, X.W.; Yuen RK, K.; Hu, Y. Flame-retardant-wrapped polyphosphazene nanotubes: A novel strategy for enhancing the flame retardancy and smoke toxicity suppression of epoxy resins. J. Hazard. Mater. 2017, 325, 327-339. [CrossRef]

21. Gouri, M.E.; Bachiri, A.E.; Hegazi, S.E.; Rafik, M.; Harfi, A.E. Thermal degradation of a reactive flame retardant based on cyclotriphosphazene and its blend with DGEBA epoxy resin. Polym. Degrad. Stabil. 2009, 94, 2101-2106. [CrossRef]

22. Liu, H.; Wang, X.D.; Wu, D.Z. Novel cyclotriphosphazene-based epoxy compound and its application in halogen-free epoxy thermosetting systems: Synthesis, curing behaviors, and flame retardancy. Polym. Degrad. Stabil. 2014, 103, 96-112. [CrossRef] 